\title{
AS IRMANDADES DA FALA E AS LINGUAS MINORITARIAS EN EUROPA DURANTE A PRIMEIRA GUERRA MUNDIAL*
}

\author{
Johannes Kabatek
}

Universität Zürich

DOI: $10.17075 /$ iftpc. 2021.005

* Quixera expresar a miña máis fonda gratitude a Xosé M. Núñez Seixas polos valiosos comentarios que achegou a unha versión anterior deste capítulo. 



\section{INTRODUCIÓN}

Coas reflexións que van a seguir sobre as Irmandades da Fala, movemento intelectual fundado en 1916 e favorable á emancipación do idioma rexional subestatal falado no noroeste de Iberia, preténdese contextualizar este movemento ao longo de dous eixes: o primeiro, o contexto contemporáneo do pensamento lingüístico e os debates sobre a diversidade das linguas a comezos do século XX; o segundo, a evolución sociodiacrónica do galego. Cen anos despois, esta lingua converteuse en idioma cooficial dunha rexión politicamente autónoma e, xunto co español, é a lingua de uso oficial, do ensino, dos medios de comunicación de masas e dun amplo abano de tradicións discursivas escritas que chegan ata a prosa científica. Trátase dun idioma «normalizado» no sentido de que, desde a década de 1980, existe un estándar escrito oficial e de que pode empregarse para calquera fin social, malia que o español goza, en xeral, dun fortísimo prestixio que fai que a miúdo o galego adopte o papel de lingua secundaria nunha situación diglósica.

A evolución histórica que desembocou na conxuntura actual tense considerado, con frecuencia, desde unha perspectiva un tanto idiosincrática, por veces acompañada duns puntos de vista anacrónicos ou teleolóxicos, segundo os cales se describe o galego como unha sorte de vítima histórica que por fin, logo de centos de anos de opresión, acadou o status que merecía. O anterior podería explicarse pola intención dos investigadores de xustificar a emancipación lingüística, mais tamén debería ser contextualizado mediante a adopción duns puntos de vista comparativos máis amplos.

Galicia é un dos numerosos territorios europeos onde, despois do declive do Imperio Romano, xurdiu do latín unha lingua vernácula rexional que, como 
outras, se espallou por motivos políticos na época medieval. O «galaicoportugués» converteuse en idioma escrito tanto de Galicia como de Portugal, pero Galicia logo se separou da súa extensión territorial portuguesa meridional, que tiña o seu novo centro en Lisboa, e ficou baixo a influencia política de León e Castela. Cando, a partir do século XV, outras linguas vernáculas europeas (comprendido o veciño portugués, ligado moi estreitamente ao galego) viviron un proceso de estandarización, o galego, como moitos idiomas europeos máis, non participou de tales procesos e dialectalizouse baixo o influxo da lingua dominante, o castelán/español. Ficou como lingua vernácula falada e a maioría rexional, monolingüe, quedou desconectada lingüisticamente da potencia hispanofalante, feito que critican durante a Ilustración unha serie de intelectuais que postulaban, como noutras rexións europeas, o acceso das clases populares á lingua e á cultura de prestixio. Igual que aconteceu en toda Europa, o século XIX trouxo consigo o que se deu en chamar «Rexurdimento» do idioma do lugar, expresado sobre todo na poesía popular, nalgúns textos en prosa e en varias reflexións metalingüísticas sobre o léxico, a gramática e a orixe da lingua, e, chegada a fin do século, como noutras rexións, distintos intelectuais desta zona vinculan o idioma á identidade do pobo e a determinados intereses político-económicos rexionais. Malia que xeograficamente distante de moitas outras rexións europeas, e malia que singular nas súas particularidades, a evolución do caso galego pode verse, xa que logo, no contexto doutros movementos rexionalistas europeos. Neste sentido, o meu relatorio céntrase principalmente nun momento clave desa evolución, os comezos do século XX, momento en que as tendencias do século anterior se integran nun programa sociolingüístico concreto sen o cal o posterior desenvolvemento do proceso sería apenas imaxinable. $\mathrm{O}$ resto do texto estrutúrase como se indica a seguir: primeiro contextualizarei o programa lingüístico xeral das Irmandades e amosarei como contradí as suposicións de conxunto do pensamento lingüístico contemporáneo; o apartado 3 está dedicado a dous principios xerais, que son, por unha banda, a transversalidade discursiva e, pola outra, o antagonismo existente entre o universalismo e o particularismo; no apartado 4 
vólvese ao particular caso galego para mostrar como a transversalidade co catalán resulta crucial para o entender, e o apartado 5 abre o contexto a outros casos europeos que se deron no mesmo período.

\section{AS IRMANDADES DA FALA E A CRENZA NO CAMBIO}

A fundación das Irmandades da Fala en 1916 coincidiu co ano de publicación, en Lausana e París, do Cours de linguistique générale de Ferdinand de Saussure, obra que comunmente se considera o documento fundacional da lingüística moderna. A xuízo de Saussure, a lingüística debería ser -seguindo a tradición dos «neogramáticos» do XIX (e o mesmo Saussure era, nun principio, neogramático)unha ciencia exacta; con todo, o seu obxecto principal (polo menos de acordo co seu famoso Cours de linguistique générale ${ }^{1}$ ) debería ser -en contra do que afirmaban os neogramáticos- o estudo da langue como sistema mental abstracto e sincrónico. Aínda que Saussure comenta polo miúdo a relación existente entre a langue obxecto e a produción da fala, a parole, tanto el como os seus seguidores estruturalistas poñen a súa atención na linguaxe como entidade autónoma diferenciada, proxección que podemos contemplar sen termos en conta a actividade «real» de falantes e ouvintes. Esta perspectiva pasou a ser a dominante na lingüística moderna e o seu fundamento atópase na teoría sociolóxica de Émile Durkheim sobre o fait social ${ }^{2}$, ao que Saussure adoitaba facer referencia nas súas aulas, xunto co pensamento psicolóxico contemporáneo. O fait social -e a linguaxe é un dos exemplos que achega Durkheim- como algo independente do individuo, quen carece da capacidade de o mudar e debe reproducir o que está

\footnotetext{
1 En realidade, a obra máis famosa de Saussure foi publicada polos seus discípulos logo do seu pasamento, e a prioridade que se lles dá aos estudos sincrónicos parece deberse máis, en parte, á intervención dos editores que á intención orixinal do autor. Canto ás críticas que recibiu, vid., entre outros, Bouquet (2012).

2 Vid. Durkheim (1982 [1895]).
} 
fixado colectivamente: «A lingua é a parte social da linguaxe, exterior ao individuo, que non pode por si só creala nin modificala; unicamente existe en virtude dunha especie de contrato establecido entre os membros da comunidade» ${ }^{3}$.

De maneira contraria ao pensamento de Saussure, as Irmandades da Fala de Galicia compartían unha visión do idioma de todo distinta. Elas propuñan empregar o galego dun xeito consciente, e facíano porque crían que, usándoo, contribuirían a unha mudanza do seu status: «Por ser a fala o elemento que mais distingue ôs pobos e mais fixa seu caraiter, e pol-o tanto, n-iste caso, o millor prá formación d'un común esprítu galeguista, a IRMANDADE porpagará por todol-os medios o emprego do noso idioma» ${ }^{4}$.

Non foi ata a segunda metade do século cando a lingüística virou a súa atención cara á interacción, a lingua e a sociedade e a planificación lingüística, para demostrar, entre outros elementos, como se pode revitalizar un idioma e como modelar o contacto lingüístico. $\mathrm{O}$ movemento das Irmandades anticipouse implicitamente a algúns dos principios da planificación lingüística moderna, xa que se caracterizaba pola crenza de que os individuos podían mudar a situación dun idioma de maneira consciente se existía unha vontade común de o facer. Aquí o que había que cambiar era, por suposto, máis a relación existente, en xeral, entre os idiomas de que se trataba (o galego fronte ao español) que as formas concretas que se daban dentro dun mesmo idioma, pero albergábase a convicción de que tiña sentido propagar a lingua e isto serviría para modificar a situación que se vivía naquela altura.

De feito, o paso máis importante que deron as Irmandades con miras á emancipación do galego consistiu en usalo tamén en contextos formais orais e escritos. Moitos dos intelectuais que participaron no Rexurdimento do XIX utilizando o galego para a poesía falaban castelán, e non aqueloutra lingua, no ámbito familiar

\footnotetext{
3 Saussure (1916: 31).

4 Irmandade da Cruña (1918): Regramento das "Irmandades da Fala», A Cruña, Imp. de la Papelera Gallega.
} 
e privado; mesmo a fundación en 1905 da Academia Galega, institución conformada a imitación doutras academias da lingua semellantes, tivo lugar en español: «Por eso, y para recoger en Galicia su verdadero léxico, dar a conocer su gramática y afirmar su existencia, se fundó esta Academia. Porque el idioma de cada pueblo es el característico más puro y poderoso de la nacionalidad [...]. [P] ueblo que olvida su idioma es un pueblo muerto [...]. Gentes que hablan la lengua que no les es propia, es un pueblo que no se pertenece» 5 .

Ata a segunda década do século XX, o castelán seguiu a ser o idioma da comunicación formal mesmo entre os defensores do galego. Esta fenda que existía entre o español como lingua formal e o galego como lingua popular pechárona as Irmandades da Fala por vez primeira na historia moderna de Galicia, ao usaren o segundo porque querían que cobrase maior importancia: así, en efecto, nas épocas precedentes do galego, os falantes recorrían a el simplemente porque era a maneira normal de se expresaren, pero agora algúns interviñan, de maneira consciente, contra a tradicional diglosia que caracterizaba a traxectoria sociolingüística da lingua ${ }^{6}$. E facíano non só dun xeito metalingüístico, tratando o idioma como obxecto externo, senón tamén incorporándoo ao seu propio comportamento lingüístico. En certo sentido, eran tanto lingüistas (xa que pensaban dunha forma consciente na planificación lingüística) como falantes, todo a un tempo, algo que resultaba completamente novo na historia do galego, e isto é o que lles outorgou e lles outorga ás Irmandades da Fala unha relevancia as fai merecedoras da súa conmemoración contemporánea, nunha época en que a planificación lingüística institucionalizada e consciente está firmemente consolidada en Galicia e se salientan na historia as raíces da situación actual.

\footnotetext{
5 Manuel Murguía (1906): «Discurso leído en la sesión inaugural de la Academia», Boletín de la Real Academia Gallega, 6-7, 125-129; vid. tamén Ínsua (2014).

6 Sobre este concepto e a historia das diglosias romances, vid. Kabatek (2016).
} 


\section{TRANSVERSALIDADE DISCURSIVA, UNIVERSALISMO E PARTI- CULARISMO}

O carácter innovador das Irmandades da Fala non se construíu só con cimentos locais, senón que tiña conexións con outros movementos sociais europeos e recibía achegas do exterior. Neste apartado preséntanse algúns conceptos xerais da lingüística variacional que servirán de pano de fondo para proceder a unha descrición desta influencia intercultural.

A lingüística non é uniforme á hora de definir as dimensións da variación lingüística. De todos os xeitos, na tradición románica acéptase, de maneira xeral, unha tripla distinción entre as variedades diatópicas (dialectais), diastráticas (sociolectais) e diafásicas (situacionais); así, unha «variedade lingüística» é unha forma de linguaxe que vén determinada polo espazo, o grupo social e a situación. Todas as variedades son «linguas», no plano funcional, pero unhas poucas son sometidas a un proceso de estandarización e pasan a ser «linguas históricas», no sentido que lles dá Coseriu (1980). Existe unha perspectiva máis recente segundo a cal se ordenan todas as variedades de acordo cunha única dimensión central e universal, ao longo do continuo que vai de «inmediatez» a «distancia» ${ }^{7}$, que son polos universais ligados ás prácticas comunicativas, as cales están caracterizadas por unha serie de condicións de interacción. Nas culturas escritas, «distancia» asóciase á lingua escrita, pero non depende dela dunha maneira causal, mentres que a «inmediatez» se vincula á lingua oral ${ }^{8}$; trátase de nocións importantes para o fin que temos entre mans, dado que, basicamente, estamos a falar do status da lingua e das variedades lingüísticas, así como do chamado Ausbau, a elevación do que antes era unha lingua da «inmediatez» aos dominios da «distancia»?.

\footnotetext{
7 Koch e Oesterreicher (2011).

8 Kabatek (no prelo).

9 Vid. Kloss (1967).
} 
Retomando o exemplo do galego moderno, vemos que, durante séculos, o idioma quedara restrinxido aos usos da «inmediatez», e o chamado Rexurdimento, o renacemento literario galego do século XIX, establecera algunhas tradicións escritas da «distancia». Porén, antes da aparición das Irmandades da Fala non houbo case ningunha tradición formal oral e, nun período moi curto, os activistas galegos conseguiron xerar un volume considerable de textos orais formais, como manifestou Antón Villar Ponte, un dos fundadores da primeira Irmandade, en 1918; ese ano "falóuse mais en galego culto que denantes n'un século» ${ }^{10}$.

$\mathrm{Na}$ lingüística moderna faise fincapé na distinción entre os enfoques «normativos» e os "descritivos», dándoselles unha clara preferencia aos segundos: a tarefa do lingüista consiste en ofrecer unha descrición e unha explicación aceptables dos fenómenos lingüísticos, non en cambiar ou modificar o obxecto ${ }^{11}$. No entanto, na tradición da lingüística, a corrente dominante probablemente sexa máis ben normativa, se pensamos nas definicións tradicionais da gramática como a arte de escribir e falar con corrección, ou nas apoloxías lingüísticas do século XVI nas que se postulaba o cambio de status dos idiomas vernáculos. A linguaxe categorízase e fálase dela non simplemente para a describir, sen tocar o obxecto, senón para conformar o obxecto de certa maneira, o que significa que os falantes son conscientes da existencia dunha relación bilateral entre a linguaxe obxecto e o discurso metalingüístico, e tamén que poden suxerir mudanzas no obxecto.

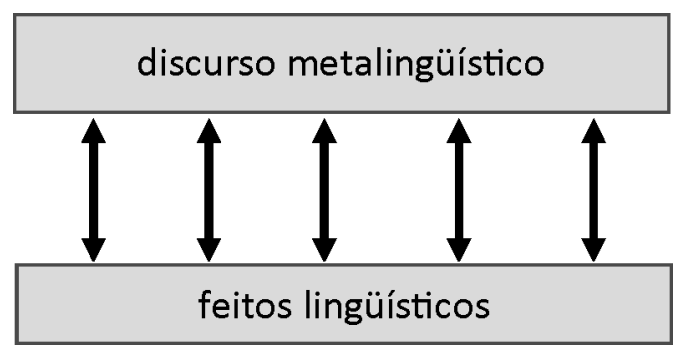

\footnotetext{
${ }^{10}$ Villar Ponte (1918), citado en Ínsua (2016: 17).

${ }^{11}$ Escusado será dicir que a pura descrición pode alterar o obxecto (na sociolingüística, por mor do que se denomina o paradoxo do observador, e mesmo na ciencia natural, se pensamos na incerteza de Heisenberg).
} 
Como sabemos polos debates sobre a planificación lingüística, as propostas de cambio lingüístico ou do prestixio da lingua non repercuten directamente no obxecto, como manifestou Einar Haugen: «O planificador propón e a comunidade dispón» ${ }^{12}$. A planificación lingüística inmediata e directa é imposible no caso das linguas naturais, non artificiais, nas que debemos considerar o triángulo que forman a planificación, a actividade lingüística e o idioma ${ }^{13}$.

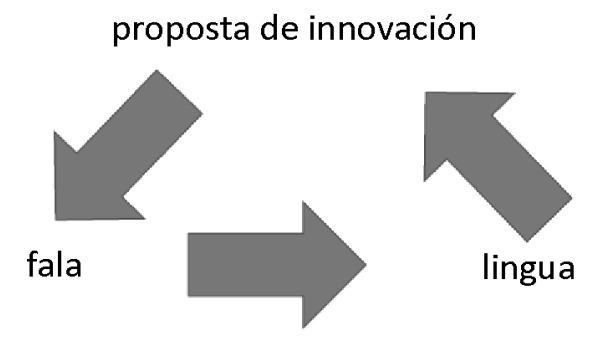

A linguaxe non é un artefacto: presupón un coñecemento colectivo e a introdución de innovacións só pode propoñerse, non impoñerse directamente. Para as innovacións se xeneralizaren, é necesario un complexo proceso de adopcións no seo da comunidade de fala, o que tamén significa que talvez a forma máis eficaz de planificación lingüística non radique en propoñer innovacións no laboratorio, senón en levar exemplos á práctica. Se volvemos de novo a mirada ás Irmandades da Fala, isto é exactamente o que fixeron: non só emitiron propostas metalingüísticas destinadas a deixar atrás aquela situación sociolingüística, senón que ademais se comportaron dun xeito innovador e emprendedor, servindo de modelo dunha concepción distinta da división das esferas lingüísticas na sociedade galega ${ }^{14}$.

\footnotetext{
12 Haugen (1966: 24).

${ }^{13}$ Kabatek (1996: 43).

${ }^{14}$ Para consultar información xeral sobre a historia do galego, vid. Monteagudo (1999). Se se desexa ter unha panorámica máis pormenorizada da traxectoria das Irmandades da Fala, vid. Beramendi (2007), Cochón (2016) e Ínsua (2016), así como o capítulo de Ramón Villares neste volume (páxinas 87-128).
} 
En xeral, baixo a premisa de que o discurso metalingüístico pode propoñer cambios nas linguas, e en función da situación concreta de que se trate, existe a posibilidade de introducir mudanzas, un abano de obxectivos viables (coas súas limitacións) que poderían acadarse. Deste xeito, a reflexión metalingüística tórnase unha cuestión política, no sentido bismarckiano da política como «a arte do posible».

Os discursos metalingüísticos que propoñen mudanzas no contexto lingüístico que se observa nun momento dado poden xerarse in situ ou ser adoptados de fóra, doutros lugares e a partir doutros exemplos, no marco dun proceso de transferencia cultural. Mediante unha análise máis demorada da historia do pensamento lingüístico, resulta posible detectar unha serie de focos de innovación nos que se constrúen ideas e modelos e desde os cales estes se espallan a outras contornas; trátase do que podemos denominar transversalidade discursiva, cando una reflexión metalingüística que se xera nunha conxuntura concreta e se deriva dela é adoptada por terceiros e se aplica a unha situación distinta:

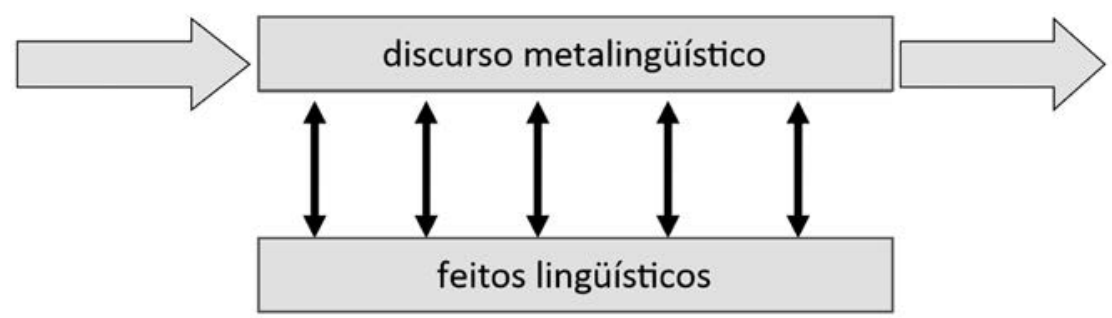

A transversalidade discursiva non só permite a adopción de análises de situacións lingüísticas noutros lugares, senón que, alén diso, facilita a adopción de propostas de cambio desas conxunturas sociolingüísticas; aínda máis, presupón comunicación, pois só se existen formas de comunicación ou contactos individuais (por veces tamén institucionais) é posible que se produza unha auténtica adopción dos discursos e a súa aplicación a unha situación nova. $\mathrm{O}$ anterior significa, así mesmo, que, ao analizar as mudanzas históricas que se dan nas 
situacións lingüísticas, ha de acharse o rastro deixado por aquelas persoas que fosen responsables da introdución de discursos innovadores ${ }^{15}$.

Outro aspecto relevante da transversalidade discursiva é o de que a situación na que apareceu orixinalmente o discurso e a situación á que se importa deben ser comparables (doutro xeito, a importación non tería sentido) e, ao mesmo tempo, algo distintas. Un discurso importado pode achar terreo fértil na situación á que se traspón, pero tamén pode enfrontarse a outras realidades ou a un rexeitamento maior que na zona orixinal, e, aínda máis, é obvio que vai mudar durante o proceso de transposición e, ao cabo, poida que sexa adaptado á situación nova, igual que Lenin adaptou o discurso marxista á sociedade agraria, para a cal non se concibira en orixe.

Ao describir a linguaxe humana, resulta útil diferenciar entre tres niveis: o universal, o histórico e o individual ${ }^{16}$. A linguaxe é o que fai que os seres humanos sexan tales e desde Aristóteles acéptase, de maneira xeneralizada, que o humano é un zoon politikón por causa do logos. Recoñecen a linguaxe humana e intuitivamente distínguena doutros ruídos; saben que en principio poderían adquirir calquera dos idiomas existentes e teñen a impresión de que entre as diversas linguas do mundo existe unha serie de características comúns. Con todo, non é posible facer referencia á «lingua» como tal; as linguas, en plural, son entidades que se desenvolveron historicamente e os seres humanos, en función da lingua ou linguas que falen, forman parte dunha historia compartida. De feito, nin sequera falamos «unha lingua», de maneira global: producimos unidades de fala individuais, situadas no tempo e no espazo.

$\mathrm{Na}$ historia do pensamento lingüístico, a linguaxe adoitaba reducirse ao nivel universal, pero o antagonismo entre o universal e o histórico desembocou tamén

\footnotetext{
${ }^{15}$ Vid. Leerssen (2006). En Kabatek (2005) mostrei, co exemplo do «Renacemento boloñés» do século XII, como se espallou por toda Europa un discurso novo que se xerara en Boloña, que potenciou, así, a creación, noutros lugares, de textos escritos en linguas vernáculas. Poderiamos mesmo inverter esa visión e afirmar que, cando de súpeto aparecían nunha rexión determinada textos vernáculos cultos, se daba por suposta a intervención dun vínculo coa "conexión Boloña».

16 Vid. Coseriu (1985).
} 
nunha oposición no discurso sobre a linguaxe. O falar constitúe sempre un acto social: só hai entendemento cando falante e ouvinte falan un idioma compartido, malia que saiban tamén que cada un deles fala dunha maneira lixeiramente distinta da do interlocutor e posúen algo que é por completo individual. O que nun plano persoal e de interacción é antagonismo entre identidade e alteridade (nun sentido hegeliano), no social reflíctese no antagonismo existente entre universalismo e particularismo. $\mathrm{O}$ universalismo a miúdo se acompaña do soño dunha lingua universal e da superación da confusión babélica: unha fusión entre os planos histórico e universal. O particularismo, pola súa parte, fai fincapé nas diferenzas, por veces reducindo o universal ao plano histórico.

A oposición entre universalismo e particularismo provén xa do mundo antigo ${ }^{17}$, pero o discurso sobre o universalismo e o particularismo lingüísticos do século XX sostense en dous elementos predominantes de épocas máis recentes, sobre todo do XVIII e do XIX: o pensamento universalista dos filósofos franceses da Ilustración, que culmina, chegada a fin do século XVIII, no principal paradigma lingüístico da Revolución Francesa, e o seu homólogo particularista, que subliña o que diferencia cada idioma concreto e a conformación das nacións de acordo coa súa diversidade lingüística, postura definida e defendida pola filosofía idealista alemá, de Herder a Wilhelm von Humboldt ${ }^{18}$.

Un obxectivo utópico da Revolución Francesa foi a propagación do francés como idioma universal, idea que tiña as súas raíces nos escritos de Étienne B. de Condillac, Antoine de Rivarol e outros autores, e que se levou á practica mediante unha serie de políticas lingüísticas aplicadas durante a segunda fase da Revolución. Anéantir les patois, "varrer os dialectos», a fórmula do abade Grégoire, constituíu tan só un dos aspectos dun completo programa de uniformación e universalización ${ }^{19}$, pois, en efecto, a política lingüística xacobina tiña o propósito

\footnotetext{
17 Bossong (1990).

18 Coseriu (2015).

19 Vid. Schlieben-Lange (1996).
} 
de purificar o francés, condenando ao esquecemento o vocabulario do Antigo Réxime. Non se tratou unicamente de que as variedades diatópicas e as demais linguas fosen consideradas inimigas da Revolución, senón que, alén diso, había que destruír a variación lingüística dependente da estratificación social, así como a diversidade de estilos, a prol do obxectivo dunha égalité lingüística carente de toda diferenza. A uniformación dos sistemas métricos, do espazo, do tempo e de calquera outro aspecto da organización cultural humana non deixou a lingua á marxe. O modelo contrario era o proposto polo Romanticismo alemán, que facía fincapé na igual dignidade de todos os idiomas e puña o seu interese na diversidade e a pluralidade na natureza e na cultura ${ }^{20}$.

A Revolución Francesa tentou, ademais, establecer un vínculo entre o universalismo lingüístico e un nesgo político, asociando o dito universalismo a unha ideoloxía progresista de esquerdas, mentres que o particularismo se ligou á reacción e á monarquía. Esta correlación segue a ser unha constante nas ideoloxías lingüísticas hoxe en día, aínda que non de maneira exclusiva; así, en contraposición con tal tendencia xeral, existen algúns movementos rexionalistas e nacionalistas subestatais, así como partidos das minorías étnicas, que tamén tentaron fusionar o particularismo cunha ideoloxía de esquerdas ${ }^{21}$. Este feito mostra que os distintos elementos discursivos poden separarse e combinarse de novo doutra forma: os irmáns Humboldt, por exemplo, simpatizaban con algunhas das premisas principais que sostiña a Revolución Francesa e tamén tiñan amigos que participaban no movemento da Idéologie, e Wilhelm von Humboldt viaxou a París logo da toma da Bastilla e mantivo correspondencia con Destutt de Tracy ${ }^{22}$. Non obstante, tanto el como Alexander unían a idea de igualdade e fraternidade co seu interese pola diversidade.

\footnotetext{
${ }^{20}$ Forster (2010).

${ }^{21}$ Vid., por exemplo, Augusteijn e Storm (2012), así como Núnez Seixas e Storm (2018).

${ }^{22}$ Gipper e Schmitter (1979).
} 
Un dos núcleos do antagonismo entre universalismo e particularismo a primeiros do século XX sería de que xeito ambos podían conxugarse con distintas ideoloxías políticas e como os movementos universalistas ou particularistas deron fusionado os seus obxectivos coa loita pola igualdade social. Os historiadores discrepan na cuestión de se a evolución do particularismo, do Romanticismo literario á súa conversión en axitación política e nun movemento de masas, representou un proceso continuo formado por varias fases (Hroch 2015) ou ben se, pola contra, debería considerarse que os pasos máis decisivos que se deron nel foron, en gran medida, autónomos con respecto ás súas raíces románticas ${ }^{23}$. Sexa como for, a evolución local de ideas e movementos que se deu nunha rexión como Galicia, con independencia da súa distancia xeográfica aos centros de referencia, non se pode entender coherentemente sen a súa relación cos discursos importados.

\section{A CONEXIÓN CATALÁ}

O movemento lingüístico galego que levou ao establecemento desta lingua como idioma falado formal e sentou as bases do que, desde a década de 1970 en diante, se denominou "normalización lingüística» constitúe un caso interesante que permite ilustrar algunhas das ideas xerais que se presentaron nos apartados anteriores.

A conexión con Francia e o pensamento francés do século XVIII estaba presente nas reflexións da Ilustración galega, época na que unha serie de intelectuais españois comentaron a necesidade de mellorar o sistema educativo ${ }^{24}$. A comezos do século XIX, despois dun longo período de escaseza ou ausencia de actividade literaria en galego, publicáronse esporadicamente algúns textos escritos

\footnotetext{
${ }^{23}$ Sobre o caso catalán, vid. Marfany (2008: 273 e ss.).

${ }^{24}$ Vid. Monteagudo (1999: 259).
} 
que serviron de fitos do inicio dunha nova tendencia rexionalista. Un exemplo interesante vén dado por Proezas de Galicia, da autoría de José Fernández Neira e impreso na Coruña no ano 1810: tratábase dun polémico diálogo antifrancés que tiña lugar no contexto da guerra de Independencia e que desempeñou a función de promover a mobilización patriótica española entre o campesiñado galego, ao que resultaba máis acaído dirixirse no seu propio idioma. Canda outros escritos contemporáneos ${ }^{25}$, este foi un dos textos que lle abriron a porta á recuperación literaria galega, o chamado Rexurdimento (un renacemento cultural), na segunda metade do século XIX.

De certo, sería difícil imaxinar o movemento das Irmandades da Fala en ausencia deste contexto. No entanto, o discurso lingüístico galego de primeiros do século XX contiña dous elementos innovadores: o propósito antes mencionado de elevar o galego aos ámbitos orais formais e o vencello entre o rexionalismo e as clases populares. Este último fenómeno xa estaba presente na poesía do XIX escrita en galego, sobre todo na obra da poetisa Rosalía de Castro, pero durante ese século non houbo ningún proxecto social definido e os protagonistas do Rexurdimento non contaban, na súa maioría, cun programa político sistemático que combinase a emancipación lingüística e a social (Hermida 1992; Beramendi 2007).

Aquelas persoas que iniciaron o movemento das Irmandades da Fala, en particular Antón Villar Ponte (1881-1936) e Aurelio Ribalta (1864-1940), merecen uns comentarios máis demorados. Villar Ponte foi o xornalista e intelectual galego que pode considerarse o seu principal fundador; denunciou a persistencia do atraso de Galicia e a esmagadora influencia do clientelismo na política rexional, e subliñou en repetidas ocasións que Cataluña, e o movemento catalán, era o modelo que había que seguir. De feito, Cataluña xa servira de modelo para a creación de Solidaridad Gallega, agrupación política fundada en 1907 como

\footnotetext{
${ }^{25}$ Mariño Paz (1992).
} 
reflexo da Solidaritat Catalana, composta por unha coalición de republicanos, catalanistas e tradicionalistas, que conseguiu gañar a maioría dos escanos cataláns nas eleccións xerais de 1907. Malia a conxuntura sociolingüística de Cataluña ser moi diferente da de Galicia, nalgúns aspectos tamén era comparable; así, a «burguesía catalá» que con frecuencia se menciona, e que se supuña que constituía o piar do movemento rexionalista, a comezos do século XX experimentara unha asimilación e era castelanfalante en gran medida. Máis aínda, non se consolidara ningún vínculo definido entre a emancipación social e a recuperación da lingua vernácula entre as clases traballadoras, que eran, nunha proporción esmagadora, falantes de catalán ${ }^{26}$; o español, grazas ao seu maior ámbito xeográfico, parecía ofrecerlles a amplos sectores da sociedade de Cataluña máis vantaxes que o catalán. No entanto, malia a Solidaritat Catalana aspirar a converterse nun movemento político panespañol dirixido contra o réxime político da monarquía da Restauración, tamén marcou un punto de inflexión, xa que o catalán pasou a estar moito máis presente que antes na vida pública. Porén, Villar Ponte, na súa adopción do discurso e as estratexias catalanistas, consideraba a lingua rexional, o galego, un elemento crucial para o reforzo da nación galega contra o "centralismo absurdo» ${ }^{27}$. O outro dirixente do movemento, Aurelio Ribalta, publicou en Madrid un ensaio sobre o "catalanismo militante» en 1901, ano da fundación da Lliga Regionalista catalá, e a principios de século mantivo intensos contactos cos intelectuais e o movemento rexionalista de Cataluña. Para el existía un claro vínculo entre o emprego da lingua rexional e un programa político rexionalista, e iniciou un debate sobre cal sería unha ortografía axeitada para o galego e é autor dunha gramática (inédita) desta lingua. O seu soño era a creación dunha Galicia libre que servise de ponte entre o veciño Portugal e Castela.

${ }^{26}$ Vid. Nagel (1991), Marfany (2001) e Anguera (1997).

${ }^{27}$ Villar Ponte (1916: 5). 
De feito, a transversalidade discursiva que se deu de Cataluña a Galicia e as frecuentes transferencias político-culturais que existiron entre Barcelona e as vilas galegas foron unha constante nos procesos de emancipación da lingua galega ao longo do século Xx. Deste xeito, durante os anos da Segunda República española (1931-1936), o Estatuto de autonomía de Galicia de 1936 baseouse en parte no modelo catalán de 1932 para establecer o castelán e o galego como idiomas oficiais (dos que o primeiro quedaba como o único que se empregaría nas relacións exteriores). De igual modo, logo da morte do xeneral Franco, os políticos nacionalistas cataláns, en alianza cos nacionalistas vascos e galegos, propuxeron a cooficialización das linguas rexionais na nova Constitución española de 1978. O modelo vixente, que comprende tres niveis de lexislación en materia de lingua (Constitución-Estatuto de autonomía-Lei de normalización lingüística), foi adoptado de Cataluña, e o discurso catalán contemporáneo sobre a independencia tamén foi imitado en parte polos nacionalistas galegos. Os cataláns teñen usado moito as plataformas internacionais, como a UNESCO, para a propagación das súas ideas, e na Carta Europea para as Linguas Rexionais ou Minoritarias exerceron unha grande influencia os representantes cataláns. Así é como o discurso lingüístico catalán se difundiu a outras rexións e os seus efectos se deixaron sentir nelas, ata o punto de que algunhas das leis sobre a diversidade lingüística que se promulgaron en América reflicten tamén certo grao de inspiración catalá. Por suposto, non se debe esaxerar a influencia catalá no discurso sobre os dereitos lingüísticos, pero si foi un dos principais focos de nacionalismo lingüístico non estatal nos albores do século XX. Pola súa parte, na década de 1970 a sociolingüística catalá adoptou firmemente unha serie de elementos procedentes do Quebec e baseou algunhas das condicións sociolingüísticas e sociopolíticas fundamentais nos modelos canadenses. 


\section{AS LINGUAS EUROPEAS NOS TEMPOS DA PRIMEIRA GUERRA MUNDIAL}

Igual que en Galicia, o universalismo e o particularismo foron as dúas forzas principais que caracterizan o antagonismo dos distintos escenarios lingüísticos europeos observados antes e despois da Primeira Guerra Mundial. Dado que neste relatorio non teño o propósito de trazar unha panorámica de todo o continente polo miúdo, vou limitar os meus comentarios a algúns aspectos xerais que amosan como debería verse o movemento galego no contexto europeo glo$\mathrm{bal}^{28}$, caracterizado por unha profunda reordenación dos espazos sociais, políticos, culturais e lingüísticos, en especial naquelas partes afectadas pola guerra de maneira directa, pero tamén alén deses territorios.

Se consideramos a vista de paxaro a evolución que se deu, no seu conxunto, a tendencia que máis destaca antes e despois da guerra é a que se inclina cara á nivelación e a homoxeneidade lingüísticas, xunto coa aparición de novas unidades políticas -Estados sucesores que actuaban como Estados nacionalizadore ${ }^{29}$ que instauraban o uso dos seus respectivos idiomas nacionais. Antes da Gran Guerra, en Europa había vinte e dous Estados independentes; no período que seguiu, a cifra ascendeu a trinta, a metade dos cales eran repúblicas, e na súa meirande parte democráticos ${ }^{30}$. O polaco foi restablecido como lingua oficial na nova República de Polonia e outros, como o checo e as distintas linguas bálticas, tamén pasaron a ser idiomas nacionais dos seus respectivos Estados nacionais nacentes, do cal un exemplo rechamante o constituíron os territorios da anterior monarquía dos Habsburgo ${ }^{31}$. Así, no século XIX e ao longo dos primeiros anos do XX, existiran nesta zona dous modelos básicos de organización lingüística:

\footnotetext{
${ }^{28}$ Para ter unha visión xeral, vid. Walker e Declercq (2016).

${ }^{29}$ Brubaker (1996).

${ }^{30}$ Vid. Grzega (2012: 70).

${ }^{31}$ Vid. Goebl (1999) e Scheer (2016).
} 
o primeiro correspondía a unha nación unificada, monolingüe e homoxénea, de inspiración francesa, e dábase desde o Compromiso (Ausgleich) de 1867 na área oriental do Imperio, a cisleitana ou húngara, onde xa se foran promulgando leis monolingües de maxiarización desde finais do século XVIII en diante; o segundo caracterizábase polo respecto á diversidade e en todos os planos das organizacións sociais estaban presentes conxuntamente varios idiomas, modelo que era corrente na zona transleitana sometida ao dominio de Viena ${ }^{32}$. Como sucedera na época da fin do Antigo Réxime, esta diversidade asociábase implicitamente coa defensa da orde social premoderna, a monarquía e a tradición.

Despois de 1918, os territorios nacentes, como Checoslovaquia e a nova República de Austria, definíronse como Estados monolingües na práctica. No caso de Checoslovaquia, o Estado-nación erixiuse sobre un construto aparentemente unificado, a chamada lingua checoslovaca, o que de facto comportaba a hexemonía do checo nun Estado plurilingüe, onde as linguas locais, como o alemán, o húngaro e o ruso, conservaban tan só algúns dos dereitos das minorías $^{33}$, que foron protexidos tamén pola Sociedade das Nacións de 1920 en diante e dos que constantemente se denunciaron violacións ante a sede de Xenebra. Tomáš G. Masaryk, presidente da República de 1918 a 1935 e un dos dirixentes máis destacados do movemento nacional checo, recibiu fortes influencias de Herder, así como da idea de que o idioma reflectía o espírito da nación; por isto, consideraba que checos e eslovacos formaban unha única nación (národ) que posuía unha lingua común (jazyk), o cal era en realidade unha ficción, pero esta idea foi defendida polas instancias oficiais desde 1918 ata a década de 1930, con intentos de evitación das diferenzas lingüísticas e con comisións de planificación lingüística que tentaron unificar a terminoloxía de ambos os idiomas.

\footnotetext{
32 Vid. Goebl (1999).

${ }^{33}$ Vid. Csernicskó e Fedinec (2015).
} 
En Francia, Italia e Alemaña considerouse que os intensos contactos que mantiveron nas trincheiras, durante a guerra, os soldados de distintas rexións, tiveron importantes consecuencias para o espertar dunha conciencia sobre a diversidade lingüística, por unha banda, e, pola outra, este trato social intensivo tamén exerceu unha forte influencia no proceso de construción dunha coherencia lingüística nacional ${ }^{34}$. Parece que a nivelación lingüística, como tendencia dominante do século XX, se acelerou nestes países en tempos de guerra e tamén despois, de tal xeito que serviu para completar o proceso de construción nacional que comezara había decenios ${ }^{35}$, e tamén foi consecuencia dun incremento nos movementos da poboación, do espallamento dos novos medios de comunicación de masas (teléfono, radio) e do aumento dos contactos lingüísticos por todo o continente. Mentres que Italia e Alemaña eran uns Estados nacionais relativamente recentes, Francia constituía, desde había moito tempo, unha unidade política cuxas tendencias unificadoras na comunicación escrita se remontaban ao século XVI; no entanto, e ao contrario do que propugnaba a mencionada ideoloxía da Revolución Francesa, a principios do XX aínda non se lograra a unidade lingüística. Non obstante, a xeneralización do ensino primario e a educación obrigatoria de 1870 en diante contribuíu en gran medida á unificación lingüística e á continuación da perda dos dialectos ${ }^{36}$; a este respecto, algúns grupos minoritarios da periferia francesa, desde a Bretaña a Córsega, influídos pola difusión do principio das nacionalidades, asumiron a defensa das linguas minoritarias, agora definitivamente ameazadas pola diseminación do idioma estatal ${ }^{37}$. No período de entre as guerras produciuse a creación de partidos que xurdiron no seo dalgúns movementos rexionalistas, como o Partido Sardo de Acción (Partito Sardo d'Azione, 1921) en Sardeña, o Partido Corso de Acción (Partitu

\footnotetext{
${ }^{34}$ Vid. Walker e Declercq (2016).

35 Vid. De Mauro (2002) e Auer et al. (2005).

36 Vid. Weber (1976) e Thiesse (1999).

37 Vid. o capítulo de Núñez Seixas neste volume (páxinas 51-86)
} 
Corsu d'Azzione, 1922) en Córsega e, varios anos despois, o Strollad Emrenerien Vreiz (Partido Autonomista Bretón, 1927) na Bretaña, os cales contaban cuns programas en parte semellantes e intercambiaron ideas principais.

A independencia política non sempre conduciu a unha verdadeira emancipación lingüística. No caso de Irlanda, a Acta constitucional do Estado Libre Irlandés, promulgada en 1922, declaraba oficial, no seu artigo 4, a lingua irlandesa como «idioma nacional» xunto co inglés, o cal, no entanto, non se consideraba un segundo «idioma nacional». $O$ irlandés converteuse na lingua do ensino e de uso oficial, pero seguiu a ser marxinal en comparación co inglés, idioma dominante. Mezo-Aranzibia (2008) compara o caso irlandés co do País Vasco, onde levou moito máis tempo oficializar a lingua vernácula e, en xeral, o idioma rexional tiña menos apoio social que en Irlanda; paradoxalmente, a política lingüística que se levou a cabo nas terras vascas, dunha maneira máis lenta e menos directa, foi máis frutífera, o que amosa a multiplicidade de factores que determinan que os intentos de dirixir a evolución lingüística desde a política resulten un éxito ou un fracaso.

Outro caso interesante foi o de Suíza, un país rodeado por outros belixerantes que conseguiu manterse neutral durante o conflito. Aquí a guerra contribuíu á preservación dun modelo distinto de nación, non baseado na unidade lingüística senón, en certa maneira, nunha identidade «negativa» que se viu reforzada polo cerco que instauraron durante o conflito unhas fronteiras fortificadas e que tamén axudou a conservar, na zona xermanofalante do país, un panorama pluridialectal de todo oposto á tendencia que era xeral en Europa, orientada cara á nivelación e a un estándar homoxéneo. Así, os dialectos do alemán son o medio normal de comunicación oral e os falantes de distintas rexións seguen a empregalos cando concorren nunha interacción lingüística, presupoñendo unha competencia pluridialectal pasiva. O alemán estándar (Hochdeutsch), pola súa vez, é unha lingua funcional para os usos escritos, así como para determinados asuntos públicos, pero rara vez se utiliza como lingua falada na esfera privada. As propostas de creación dun estándar de alemán suízo foron totalmente marxinais, 
dado que a condición de suízo se expresa mediante o uso dos dialectos e de acordo cuns trazos de identidade político-ideolóxicos non lingüísticos ${ }^{38}$.

Poderían engadirse máis casos. O que teñen en común os discursos de moitos lugares é que existe unha situación dinámica na que se producen movementos sociais e o establecemento de ordes novas que inflúen nas linguas e nas variedades lingüísticas e que se valen delas como argumentos para a consecución dos seus obxectivos. E nesas ordes parece existir a convicción, contraria á idea de inconsciencia da mudanza lingüística que manifestan unha serie de lingüistas contemporáneos, de que as situacións lingüísticas poden cambiarse e os idiomas planificarse. A este respecto, o círculo lingüístico de Praga constitúe un exemplo interesante de como un único grupo de lingüistas se enfronta a esta aparente contradición: os fonólogos de Praga son os sucesores máis inmediatos da doutrina de Ferdinand de Saussure e, ao mesmo tempo, outros integrantes do grupo dedícanse á estandarización da lingua literaria checoslovaca e á súa elevación a un nivel culto. En Galicia, a práctica lingüística e o programa social das Irmandades da Fala coinciden tamén con determinadas actividades metalingüísticas e propostas ortográficas, como a ortografía fonética de Aurelio Ribalta para o galego, presentada en 1910 no seu Libro de Konsagrazión: a idea que comparten é a de que as linguas poden planificarse de maneira interna, con referencia ao corpus, e externa, con referencia ao seu status ${ }^{39}$.

\section{CONCLUSIÓNS}

As Irmandades da Fala foron, sen dúbida, un movemento moi peculiar, pero forman parte dunha historia lingüística europea común, na cal distintos idiomas naceron, morreron, se emanciparon, dexeneraron, e todo por mor da actividade

).

38 Vid. Zimmer (2003, 2005), así como Werlen (1993) e Christen (1998, 2010). 
dos seus falantes, así como de resultas da creación, adopción e reprodución duns discursos ideolóxicos. Os acontecementos históricos internacionais, como as repercusións que tivo a Primeira Guerra Mundial, exerceron uns efectos destrutivos e deixaron millóns de vítimas nos campos de batalla, xunto con familias esfameadas no rural e na retagarda; porén, o caos da guerra ocasionou, así mesmo, trastornos políticos, a morte da vella orde que se identificaba co longo século XIX e a aparición de ordes novas e a emancipación dos reprimidos, como afirmou tamén Antón Villar Ponte: «Acaso este gran mal de la guerra monstruosa en cuya vorágine, más o menos, danzamos todos concluya por traernos enormes bienes. No importa que sea a costa de tantos dolores inenarrables y de tantas lágrimas y sufrimientos. A todo gran ideal se llega siempre luego de haber dejado a la espalda una nueva vía Apia orillada de cruces» ${ }^{40}$.

Eu non comparto a opinión de Villar Ponte de que era necesario pasar por momentos terribles para construír unha orde nova, como no Deutsches Requiem de Jorge Luis Borges (incluído na súa obra El Aleph, de 1949) ou naquel «naceu unha beleza terrible» de Yeats, referido ao Alzamento irlandés (1916). Aquela guerra monstruosa non ía ser a derradeira do século e o soño de igualdade social de Villar Ponte, así como o dunha sociedade galega en que se falase o galego en todos os ámbitos, aínda ía tardar moito en se facer realidade, e nós seguimos sen saber se as Irmandades non chegaron simplemente demasiado tarde.

Ata ben entrado o século XX, Galicia foi un territorio case monolingüe, no que só unhas reducidas elites falaban español nas súas interaccións diarias e a gran maioría empregaba en exclusiva o galego. Porén, as tendencias orientadas a inverter esta situación, un tanto marxinais, que se observaron desde o século XIX en diante enfrontáronse a outras intensamente castelanizantes no século XX. Aínda que se produciu un intento de oficializar o galego durante a Segunda República, que case chegou a bo porto e fracasou debido a que non chegou a aplicarse o

${ }^{39}$ Vid. Ribalta (1910). 
Estatuto galego de autonomía, aprobado en referendo tres semanas antes do estalido da Guerra Civil, as dúas ditaduras españolas (1923-1930 e 1939-1975) que dominaron o século (principalmente o réxime franquista e as súas políticas lingüísticas unificadoras) contribuíron con forza á diseminación dunha castelanización en grande escala. A modernización económica da posguerra asociouse case en exclusiva ao español, mentres que o galego foi quedando, cada vez máis, como lingua falada polo campesiñado e as xeracións máis vellas; e a diglosia intrafamiliar, na que uns adultos máis ou menos bilingües tentan educar os fillos no idioma dominante, ao tempo que falan en galego só con outros adultos, tornouse un fenómeno cada vez máis frecuente. A democratización que seguiu á morte de Franco permitiu tamén unha renacenza do galego e a Constitución de 1978 serviu de marco legal para a emancipación política e a «normalización lingüística», de maneira que o galego pasou a ser a lingua cooficial da "Comunidade Autónoma» de Galicia e o idioma do Parlamento autonómico, da instrución pública e dos medios de comunicación de masas. No entanto, o proceso de asimilación lingüística seguiu avanzando e ningunha das medidas políticas que se puxeron en marcha conseguiu inhibir unha tendencia que amosa un constante cambio lingüístico cara ao español ${ }^{41}$. Un século despois, Antón Villar Ponte e os fundadores das Irmandades da Fala recoñecerían, con certeza, que se cumpriron algunhas das súas demandas, mais ao tempo non gustarían dalgúns dos procesos lingüísticos que teñen lugar na Galicia actual.

\footnotetext{
${ }^{40}$ Villar Ponte (1917), citado en Ínsua (2016: 47).

${ }^{41}$ Vid. Consello da Cultura Galega (2005).
} 


\section{REFERENCIAS BIBLIOGRÁFICAS}

Anguera, Pere (1997): El català al segle XIX, Barcelona, Empúries.

Auer, Peter / Frans Hinskens / Paul Kerswill (eds.) (2005): Dialect Change: Convergence and Divergence in European Languages, Cambridge, Cambridge University Press.

Augusteijn, Joost / Eric Storm (eds.) (2012): Region and State in Nineteenth-Century Europe: Nation-Building, Regional Identities and Separatism, Basingstoke, Palgrave Macmillan.

BERAMENDI, Justo G. (2007): De provincia a nación: historia do galeguismo político, Vigo, Xerais.

Bossong, Georg (1990): Sprachwissenschaft und Sprachphilosophie in der Romania: von den Anfängen bis August Wilhelm Schlegel, Tübingen, Narr.

BOUQUET, Simon (2012): «Principes d'une linguistique de l'interprétation : une épistémologie néosaussurienne», Langages, 185, 21-33.

BRUBAKER, Rogers (1996): Nationalism Reframed: Nationhood and the National Question in the New Europe, Cambridge, Cambridge University Press.

Christen, Helen (1998): «Convergence and Divergence in the Swiss German Dialects», Folia Linguistica, 32:1-2, 53-67.

Christen, Helen (2010): «Vertikale und horizontale Variation: Beobachtungen zum Schweizerdeutschen», en Peter Gilles / Joachim Scharloth / Evelyn Ziegler (eds.), Variatio delectat: empirische Evidenzen und theoretische Passungen sprachlicher Variation: für Klaus J. Mattheier zum 65. Geburtstag, Frankfurt am Main / Berlin / Bern / Bruxelles / New York / Oxford / Wien, Peter Lang, 145-159.

COCHÓN, Luís (ed.) (2016): Arredor das Irmandades da Fala: pensamento, politica e poética en Galicia (1914-1931), Vigo, Xerais.

Consello da Cultura Galega (2005): A sociedade galega e o idioma: evolución sociolingüistica de Galicia (1992-2003), Santiago de Compostela (http://consellodacultura.gal/mediateca/extras/CCG_2005_ A-sociedade-galega-e-o-idioma-evolucion-sociolinguistica-de-Galicia-1992-2003.pdf).

Coseriu, Eugenio (1980): “Historische Sprache' und 'Dialekt’», en Joachim Göschel / Pavle Ivic / Kurt Kehr (eds.), Dialekt und Dialektologie, Wiesbaden, Steiner, 106-116.

CoserIU, Eugenio (1985): «Linguistic Competence: What Is It Really?», The Presidential Address of the Modern Humanities Research Association read at University College, London, on 11 January 1985, The Modern Language Review, 80:4, xxv-xxxv.

Coseriu, Eugenio (2015): Geschichte der Sprachphilosophie: Band 2: Von Herder bis Humboldt, ed. de Jörn Albrecht, Tübingen, Narr.

Csernicskó, István / Csilla Fedinec (2015): «Language and Language Policy in Transcarpathia between the Two World Wars", Minority Studies: Demography, Minority Education, Ethnopolitics, 18, 93-113.

Forster, Michael Neil (2010): After Herder: Philosophy of Language in the German Tradition, Oxford, Oxford University Press.

DurkHeIm, Émile ([1895] 1982): The Rules of Sociological Method: And Selected Texts on Sociology and its Method, ed. de S. Lukes, New York, Free Press.

Gipper, Helmut / Peter SCHMITTER (1979): Sprachwissenschaft und Sprachphilosophie im Zeitalter der Romantik, Tübingen, Narr.

GoEBL, Hans (1999): «Die Sprachensituation in der Donaumonarchie», en Ingeborg Ohnheiser / Manfred Kienpointner / Helmut Kalb (eds.), Sprachen in Europa: Sprachsituation und Sprachpolitik in europäischen Ländern, Innsbruck, Institut für Sprachwissenschaft, 33-58. 
GrZEGA, Joachim (2012): Europas Sprachen und Kulturen im Wandel der Zeit: eine Entdeckungsreise, Tübingen, Stauffenburg.

Haugen, Einar (1966): Language Conflict and Language Planning: The Case of Modern Norwegian, Cambridge, Mass., Harvard University Press.

Hermida, Carme (1992): Os precursores da normalización: defensa e reivindicación da lingua galega no Rexurdimento (1840-1891), Vigo, Xerais.

Hroch, Miroslav (2015): European Nations: Explaining their Formation, London, Verso.

ÍnsUA, Emilio Xosé (2014): Antón Villar Ponte e a Academia Galega: contributos para a historia crítica dunha institución centenaria, Vigo, Edicións do Cumio.

ÍnsuA, Emilio Xosé (2016): A nosa terra é nosa!: a xeira das Irmandades da Fala (1916-1931), A Coruña, Baía.

KABATEK, Johannes (1996): Die Sprecher als Linguisten: Interferenz- und Sprachwandelphänomene dargestellt am Galicischen der Gegenwart, Tübingen, Niemeyer.

KABATEK, Johannes (2005): Die Bolognesische Renaissance und der Ausbau romanischer Sprachen: juristische Diskurstraditionen und Sprachentwicklung in Südfrankreich und Spanien im 12. und 13. Jahrhundert, Tübingen, Niemeyer.

KABATEK, Johannes (2016): «Diglossia», en Adam Ledgeway / Martin Maiden (eds.), The Oxford Guide to the Romance Languages, Oxford, Oxford University Press, 624-633.

KABATEK, Johannes (no prelo): «Spoken and written language», en Xulio Sousa / Ernesto González Seoane (eds.), Manual of Galician Linguistics, Berlin, De Gruyter.

KLoss, Heinz (1967): “Abstand Languages' and 'Ausbau Languages'», Anthropological Linguistics, 9:7, $29-41$.

Koch, Peter / Wulf OesterreICher (2011): Gesprochene Sprache in der Romania: Französisch, Italienisch, Spanisch, Berlin, De Gruyter.

LeERSSEN, Joep (2006): National Thought in Europe: A Cultural History, Amsterdam, Amsterdam University Press.

MARFANY, Joan-Lluís (2001): La llengua maltractada: el castellà i el català a Catalunya del segle XVI al segle XIX, Barcelona, Empúries.

MARFANY, Joan-Lluís (2008): Llengua, nació i diglossia, Barcelona, L’Avenç.

MARIÑO PAZ, Ramón (1992): Estudio fonético, ortográfico e morfolóxico de textos do prerrexurdimento galego (1805-1837), tese de doutoramento, Santiago de Compostela, Universidade.

MAUro, Tullio de (2002): Storia linguistica dell'Italia unita, Bari, Laterza.

Mezo-ARAnZiBIA, Josu (2008): El palo y la zanahoria: política lingüistica y educación en Irlanda (1922-1939) y el País Vasco (1980-1998), Madrid, Centro de Estudios Políticos y Constitucionales.

Monteagudo, Henrique (1999): Historia social da lingua galega: idioma, sociedade e cultura a través do tempo, Vigo, Galaxia.

NAGEL, Klaus-Jürgen (1991): Arbeiterschaft und nationale Frage in Katalonien zwischen 1898 und 1923, Saarbrücken / Fort Lauderdale, Breitenbach.

NúNEz SeIXAS, Xosé M. / Eric STORM (eds.) (2018): Regionalism and Modern Europe: Identity Construction and Movements from 1890 to the Present Day, London, Bloomsbury.

Ribalta, Aurelio (1901): Catalanismo militante, Madrid, Imprenta de Romero. 
Ribalta, Aurelio (1910): Libro de Konsagrazión: feixe de poesías gallegas, Madrid, Sucesores de Hernando. SAussure, Ferdinand de ([1916] 1984): Cours de linguistique générale, ed. de Tullio de Mauro (1ª ed.: 1972, baseada na edición orixinal de Charles Bally, Albert Sechehaye e Albert Riedlinger, de 1916), Lausanne / Paris, Payot.

SCHEER, Tamara (2016): «Habsburg Languages at War: "The linguistic confusion at the tower of Babel couldn't have been much worse"”, en Julian Walker / Christophe Declercq (eds.), Languages and the First World War: Communicating in a Transnational War, Basingstoke, Palgrave Macmillan, 62-78.

SChlieben-Lange, Brigitte (1996): Idéologie, révolution et uniformité de la langue, Sprimont, Mardaga.

ThIESSE, Anne-Marie (1999): La Création des identités nationales : Europe XVIII -XXe siècle, Paris, Seuil.

VILlar PONTE, Antón (1916): Nacionalismo gallego: nuestra afirmación regional, A Coruña, Tipografía Obrera.

WALKeR, Julian / Christophe DeClerCQ (eds.) (2016): Languages and the First World War: Communicating in a Transnational War, Basingstoke, Palgrave Macmillan.

Weber, Eugen (1976): Peasants into Frenchmen: The Modernization of Rural France, 1870-1914, Stanford, Stanford University Press.

Werlen, Iwar (ed.) (1993): Schweizer Soziolinguistik - Soziolinguistik der Schweiz, núm. 58 do Bulletin CILA, Neuchâtel, Institut de linguistique de l'Université de Neuchâtel.

Zimmer, Oliver (2003): A Contested Nation: History, Memory and Nationalism in Switzerland, 1761-1891, Cambridge, Cambridge University Press.

ZIMMER, Oliver (2005): «Nation, nationalism and power in Switzerland, c. 1760-1900», en Len Scales (ed.), Power and the Nation in European History, Cambridge, Cambridge University Press, 333-353. 